\title{
ANALISA STRATEGI EMPLOYER BRANDING TERHADAP MINAT MELAMAR KERJA
}

\author{
Irene Reinardus Indra \\ Program Studi Magister Manajemen Universitas Tarumanagara \\ irenereinardus15@gmail.com \\ Sawidji Widoatmodjo \\ Program Studi Magister Manajemen Universitas Tarumanagara
}

Masuk : 26-11-2020, revisi : 16-12-2020 diterima untuk diterbitkan : 17-12-2020

\begin{abstract}
The objective of this study is to acknowledge employer branding strategies for companies in Indonesia to attract intention to apply from prospective fresh graduates by analyzing the impact of employer attractiveness and social media usage to corporate reputation directly and to intention to apply indirectly through corporate reputation and also the impact of corporate reputation to intention to apply. The sample of this study is 297 college students in who will become fresh graduates in next 1-2 years. Structural equation modeling is used in the hypothesis testing. The result of the study shows that development value of employer attractiveness and social media usage have significant positive impact on corporate reputation directly and on intention to apply indirectly. Corporate reputation itself has significant positive impact on intention to apply. In conclusion, companies in Indonesia should pay attention to development value and consider using social media in designing their employer branding strategies to attract fresh graduates to apply for jobs in the companies.
\end{abstract}

Abstrak: Penelitian ini bertujuan untuk mengetahui strategi employer branding bagi perusahaan di Indonesia dalam menarik minat melamar kerja dari fresh graduates dengan menganalisis pengaruh daya tarik perusahaan dan penggunaan media sosial terhadap reputasi perusahaan secara langsung dan minat melamar secara tidak langsung melalui reputasi perusahaan dan juga dampak reputasi perusahaan terhadap minat melamar kerja. Penelitian ini menggunakan sampel 297 mahasiswa yang akan menjadi fresh graduates dalam 1-2 tahun ke depan. Uji hipotesis dilakukan dengan structural equation modeling. Hasil penelitian menunjukkan bahwa daya tarik perusahaan dimensi development value dan penggunaan media sosial berpengaruh signifikan positif terhadap reputasi perusahaan secara langsung dan terhadap minat melamar kerja secara tidak langsung. Reputasi perusahaan sendiri memiliki pengaruh signifikan positif terhadap minat melamar kerja. Maka, perusahaan di Indonesia perlu memperhatikan dimensi development value dan mempertimbangkan penggunaan media sosial dalam merancang strategi employer branding untuk menarik fresh graduates melamar pekerjaan di perusahaan.

Keywords: Employer Branding, Social Media Usage, Corporate Reputation, Intention to Apply

\section{PENDAHULUAN}

"The best workers do the best and the most work. But many companies do an awful job of finding and keeping them" (Keller \& Meaney, 2017). Saat ini, perusahaan menghadapi war for talent dimana perusahaan harus memiliki kemampuan untuk membuat pekerja-pekerja yang kompeten tertarik bekerja di perusahaan supaya bisa memenangkan persaingan (Aslam, 2015). Perusahaan saat ini juga dihadapkan pada generasi baru calon pekerja, yaitu generasi $\mathrm{Z}$ yang memiliki karakteristik berbeda dengan generasi sebelumnya, di antaranya. Deloitte dalam 
penelitian di tahun 2019 menemukan bahwa generasi Z tidak begitu menganggap gaji sebagai faktor penting dalam memilih pekerjaan, mencari kepastian, keamanan kerja, dan pengembangan diri yang dapat dilakukan dengan bekerja di perusahaan, serta tidak dapat lepas dari internet dan teknologi komunikasi, di antaranya dalam bentuk media sosial. Selain itu, perusahaan juga menghadapi perkembangan teknologi komunikasi khususnya media sosial. Adanya war for talent disertai perubahan karakteristik generasi calon pekerja membuat perusahaan perlu membedakan diri dari pesaing supaya menarik minat calon pekerja berkualitas untuk melamar ke perusahaan. Pembedaan diri dapat dilakukan dengan membangun reputasi positif melalui penciptaan employer branding berdasarkan daya tarik perusahaan dan penggunaan media sosial. Maka, penelitian ini dilakukan dengan harapan dapat memberi wawasan baru kepada perusahaan dalam menyusun strategi employer branding sesuai dengan daya tarik perusahaan dan media sosial yang dianggap menarik untuk menciptakan reputasi perusahaan yang baik dan mendorong calon pekerja potensial melamar kerja ke perusahaan. Penelitian ini menggunakan penelitian Sivertzen, Nilsen, \& Olafsen (2013) dengan judul "Employer Branding: Employer Attractiveness and The Use of Social Media" sebagai rujukan utama yang menemukan bahwa dari tiga dimensi daya tarik perusahaan yaitu, innovation value, psychological value, dan application value serta penggunan sosial media memiliki hubungan positif dengan reputasi perusahaan dan minat melamar kerja.

\section{Tujuan Penelitian}

Penelitian ini bertujuan untuk mengetahui (1) pengaruh daya tarik perusahaan terhadap reputasi perusahaan; (2) pengaruh penggunaan media sosial oleh perusahaan terhadap reputasi perusahaan; (3) pengaruh reputasi perusahaan terhadap minat melamar kerja; (4) pengaruh daya tarik perusahaan terhadap minat melamar kerja melalui reputasi perusahaan; (5) pengaruh penggunaan media sosial oleh perusahaan terhadap minat melamar kerja melalui reputasi perusahaan; (6) strategi yang dapat dilakukan perusahaan untuk menarik minat calon pekerja melamar kerja ke perusahaan.

\section{TINJAUAN PUSTAKA}

\section{Resource-Based View Theory}

Resource-Based View Theory menekankan pada penemuan sumber daya tertentu dalam perusahaan yang membuat perusahaan dapat memiliki keunggulan kompetitif berkelanjutan dibanding perusahaan lain dalam industri yang sama yang mencakup tiga kategori, yaitu sumber daya fisik, manusia, dan perusahaan (David \& David, 2017).

\section{Employer Branding}

Employer branding pada prinsipnya merupakan penciptaan brand yang menarik perhatian, relevan, dan unik serta memberi dampak positif (Moroko \& Uncles, 2008). Brand diciptakan berdasarkan faktor unik yang ada dalam perusahaan atau employer value proposition (Gehrels, 2019).

\section{Daya Tarik Perusahaan}

Daya tarik perusahaan merupakan manfaat yang dibayangkan akan diterima calon pekerja potensial dengan bekerja di suatu perusahaan. (Berthon, Ewing, \& Hah, 2005). Ada lima faktor yang menjadi ukuran daya tarik perusahaan yaitu : (1) interest value atau lingkungan kerja menantang, praktik kerja baru, dan pengembangan kreativitas; (2) social value atau lingkungan kerja yang menyenangkan, hubungan baik antar anggota perusahaan, dan kerjasama tim; (3) economic value atau gaji di atas rata-rata, paket kompensasi, keamanan kerja, dan kesempatan promosi, (4) development value atau adanya pengakuan, peningkatan kepercayaan diri, kesempatan menambah pengalaman karir, dan menjadi batu loncatan untuk pekerjaan berikutnya; (5) application value atau adanya kesempatan bagi karyawan menerapkan apa yang sudah dipelajari dan berbagi kepada orang lain. 


\section{Media Sosial}

Media sosial merupakan sarana komunikasi dan kolaborasi online di antara jaringan orang, komunitas, dan organisasi yang saling terhubung dan saling tergantung yang dilengkapi dengan kapabilitas teknologi dan mobilitas (Tuten \& Solomon, 2014).

\section{Reputasi Perusahaan}

Reputasi perusahaan dapat diartikan sebagai evaluasi kolektif oleh individu-individu berbeda berdasarkan perilaku perusahaan yang menentukan apakah individu menyukai atau tidak menyukai perusahaan. Reputasi perusahaan menghasilkan keunggulan kompetitif dengan menciptakan identitas perusahaan yang unik dan berbeda (Carrol, 2016).

\section{Minat Melamar Kerja}

Minat melamar kerjadilihat dari perspektif organizational attractiveness menekankan pada kemampuan image perusahaan yang sukses untuk menarik minat lebih banyak pencari kerja dan meningkatkan minat melamar kerja mereka. Semakin baik image perusahaan, semakin tinggi kecenderungan pencari kerja untuk melamar kerja ke perusahaan (Wei, Chang, Lin, \& Liang, 2015).

\section{METODOLOGI PENELITIAN}

Penelitian ini menggunakan data primer yang dikumpulkan melalui penyebaran kuesioner elektronik selama lima minggu yang diukur dengan skala Likert 1-7 dan menghasilkan sampel 297 mahasiswa Indonesia semester 5-8. Ada empat variabel penelitian dan tiga puluh delapan indikator yang menjadi pertanyaan dalam kuesioner, yaitu daya tarik perusahaan yang memiliki lima dimensi yaitu interest value, social value, economic value, development value, dan application value dengan masing-masing lima indikator (Berthon, Ewing, \& Hah, 2005), penggunaan media sosial dengan empat indikator (Collins \& Stevens, 2002), reputasi perusahaan dengan empat indikator (Turban, Forret, \& Hendrickson, 1998), dan minat melamar kerja dengan lima indikator (Highhouse, Lievens, \& Sinar, 2003). Pengujian dilakukan menggunakan structural equation modeling dengan bantuan aplikasi SPSS Amos 24 dan teknis analisis maximum likelihood estimation. Berikut adalah model yang digunakan dalam penelitian ini :

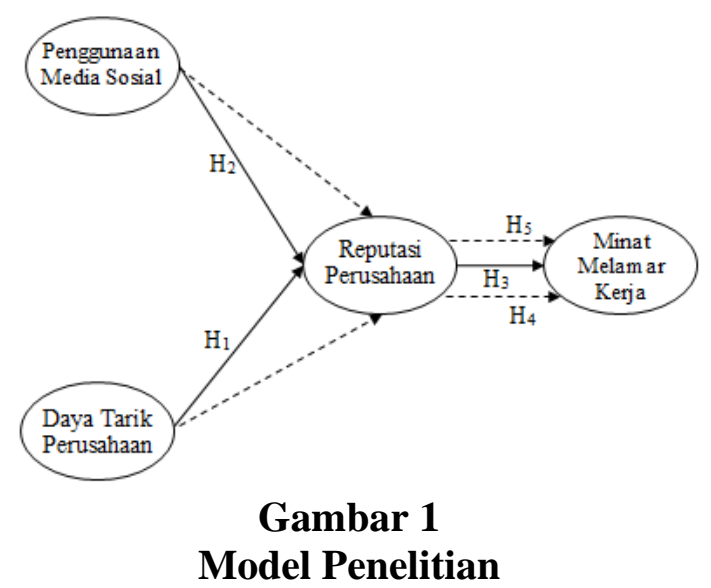

Sebelum kuesioner didistribusikan, terlebih dahulu dilakukan pretest kuesioner kepada 20 responden dengan karakteristik yang mirip dengan sampel. Dari hasil pretest diperoleh 36 indikator yang valid dan siap digunakan dalam uji sesungguhnya, dimana ada 1 indikator daya tarik perusahaan dan 1 indikator reputasi perusahaan yang tidak valid.

\section{HASIL DAN KESIMPULAN Statistik Deskriptif}

Dari 297 responden, sebanyak 242 merupakan wanita dan 55 sisanya pria, 237 di antaranya berusia 20-21 tahun dan 35 orang berusia di bawah 20 tahun, 24 orang berusia 2223 tahun, dan 1 orang berusia di atas 23 tahun, 146 di antaranya ada di semester 5, 24 orang 
ada d semester 6, 107 orang ada di semester 7, dan 20 orang ada di semester 8. Dari total 297 responden, media sosial pilihan pertama dan kedua untuk menyampaikan informasi terkait perusahaan sekaligus promosi adalah websites dan Instagram.

\section{Uji Hipotesis}

Uji pada penelitian ini dilakukan menggunakan fitur bootstrap karena data tidak memenuhi asumsi normalitas (Streukens \& Leroi-Werelds, 2015) sekaligus untuk menguji hubungan tidak langsung (Hair, Black, Babin, \& Anderson, 2014). Sebelum dilakukan uji hipotesis, terlebih dahulu dilakukan uji validitas model pengukuran dan model struktural serta uji goodness-of -fit. Pada uji validitas pertama ditemukan ada empat indikator yang tidak valid yaitu 1 indikator social value, 2 indikator economic value, dan 1 indikator penggunaan media sosial. Setelah keempat indikator tersebut dikeluarkan, diperoleh hasil bahwa 32 indikator penelitian valid dengan nilai factor loadings lebih besar dari 0.05 dan nilai $p$-value $<0.05$ dan reliabel dengan nilai construct reliability $\mathrm{CR}>0.7$ walau ada nilai average variance extracted AVE $<0.5$ (Fornell \& Larcker, 1981). Setelah seluruh indikator valid dan reliabel, dilakukan uji goodness-of-fit. Dengan hasil uji goodness $=$ of-fit yaitu nilai CMIN/df $=2.099$ (cut-off $\leq 3)$, RMSEA $=0.061$ (cut-off $\leq 0.07)$, TLI $=0.853$ (cut-off $\geq 0.90)$, dan CFI $=0.869$ (cut-off $\geq 0.90)$, maka model memenuhi kriteria goodness-of-fit dan dapat dilanjutkan ke uji hipotesis. Hasil uji hipotesis disajikan dalam tabel 1.1. Dari hasil uji hipotesis yang tersaji dalam tabel 1.1, dapat diketahui bahwa dari 5 hipotesis yang diajukan dalam penelitian ini, 3 hipotesis diterima, sedangkan 2 hipotesis lainnya diterima sebagian, dengan rincian sebagai berikut :

1. $\mathrm{H}_{1}$ : Daya tarik perusahaan memiliki pengaruh positif terhadap reputasi perusahaan $\mathrm{H}_{1}$ diterima sebagian dimana $\mathrm{H}_{1}$ diterima untuk dimensi development value ( $p$-value $=$ $0.031<0.05)$ tetapi ditolak ( $p$-value > 0.05$)$ untuk dimensi interest value, social value, economic value, dan application value. Hal ini berarti mahasiswa Indonesia calon fresh graduates memprioritaskan kesempatan pengembangan diri ketika mencari perusahaan tempat bekerja dan memandang perusahaan yang bisa menawarkan atribut tersebut memiliki reputasi baik. Hal ini sejalan dengan penelitian Sivertzen, Nilsen, \& Olafsen (2013), Babikova \& Bucek (2019), dan Eger, Micik, Gangur, \& Rehor (2018).

2. $\mathrm{H}_{2}$ : Penggunaan media sosial oleh perusahaan memiliki pengaruh positif terhadap reputasi perusahaan

$\mathrm{H}_{2}$ diterima $(p$-value $=0.000<0.05)$ berarti penggunaan media sosial mendorong terciptanya reputasi perusahaan yang baik. Hal ini sejalan dengan penelitian Sivertzen, Nilsen, \& Olafsen (2013), Priyadarshini, Kumar, \& Jha (2017), dan Kissel \& Buttgen (2015).

3. $\mathrm{H}_{3}$ : Reputasi perusahaan memiliki pengaruh positif terhadap minat melamar kerja $\mathrm{H}_{3}$ diterima ( $p$-value $=0.000<0.05$ ) berarti reputasi perusahaan yang baik meningkatkan minat melamar kerja. Hal ini sejalan dengan penelitian Sivertzen, Nilsen, \& Olafsen (2013), Chhabra \& Sharma (2014), Backhaus (2016), dan Khalid \& Tariq (2015).

4. $\mathrm{H}_{4}$ : Daya tarik perusahaan memiliki pengaruh positif terhadap minat melamar kerja melalui reputasi perusahaan

$\mathrm{H}_{4}$ diterima sebagian dimana $\mathrm{H}_{4}$ diterima untuk dimensi development value ( $p$-value $=$ $0.038<0.05)$ tetapi ditolak ( $p$-value $>0.05$ ) tetapi ditolak untuk dimensi interest value, social value, economic value, dan application value. Hal ini berarti adanya atribut development value menarik bagi calon fresh graduates dan akan menarik minat mereka melamar kerja ke perusahaan karena memandang perusahaan memiliki reputasi yang baik. Hal ini sejalan dengan penelitian Sivertzen, Nilsen, \& Olafsen (2013), Kissel \& Buttgen (2015), dan Eger, Micik, Gangur, \& Rehor (2018). 
Tabel 1

Hasil Uji Hipotesis

\begin{tabular}{|c|c|c|c|c|}
\hline Hipotesis & Indikator & Estimates & $P$-value & Hasil Uji \\
\hline $\mathrm{H} 1$ & $\begin{array}{l}\text { CR }<-- \text { EA } \\
-C R<--I V \\
-C R<-- \text { SV } \\
-C R<---E V \\
-C R<--D V \\
-C R<--A V\end{array}$ & $\begin{array}{l}-0.097 \\
0.297 \\
0.010 \\
0.397 \\
0.122 \\
\end{array}$ & $\begin{array}{l}0.474 \\
0.113 \\
0.890 \\
0.031 \\
0.320\end{array}$ & $\begin{array}{c}\text { Ditolak } \\
\text { Ditolak } \\
\text { Ditolak } \\
\text { Diterima } \\
\text { Ditolak }\end{array}$ \\
\hline $\mathrm{H} 2$ & CR $<--$ SM & 0.407 & 0.000 & Diterima \\
\hline $\mathrm{H} 3$ & IA $<---C R$ & 0.631 & 0.000 & Diterima \\
\hline $\mathrm{H} 4$ & $\begin{array}{l}\text { IA }<--C R<-- \text { EA } \\
-I A<--C R<-- \text { IV } \\
-I A<--C R<-- \text { SV } \\
-I A<--C R<-- \text { EV } \\
-I A<--C R<-- \text { DV } \\
-I A<--C R<--A V\end{array}$ & $\begin{array}{l}-0.042 \\
0.083 \\
0.007 \\
0.152 \\
0.072\end{array}$ & $\begin{array}{l}0.498 \\
0.188 \\
0.879 \\
0.038 \\
0.509\end{array}$ & $\begin{array}{c}\text { Ditolak } \\
\text { Ditolak } \\
\text { Ditolak } \\
\text { Diterima } \\
\text { Ditolak }\end{array}$ \\
\hline H5 & IA $<---$ CR $<---$ SM & 0.233 & 0.002 & Diterima \\
\hline
\end{tabular}

5. $\mathrm{H}_{5}$ : Penggunaan media sosial memiliki pengaruh positif terhadap minat melamar kerja melalui reputasi perusahaan

$\mathrm{H}_{5}$ diterima $(p$-value $=0.002<0.05)$ berarti penggunaan media sosial mendorong peningkatan minat melamar kerja melalui terciptanya reputasi perusahaan yang baik dan lebih dikenalnya perusahaan. Hal ini sejalan dengan penelitian Sivertzen, Nilsen, \& Kesimpulan

Olafsen (2013), Kissel \& Buttgen (2015), dan Katiyar \& Saini (2016).

Jadi, mahasiswa Indonesia calon fresh graduates menganggap penting dan menarik daya tarik perusahaan dimensi development value sejalan dengan karakteristik mahasiswa sebagai generasi Z (Singh \& Dangmei, 2016) serta lebih tertarik pada perusahaan yang menggunakan media sosial dalam menyampaikan informasi. Maka, perusahaan di Indonesia perlu mempertimbangkan mengutamakan development value dan menggunakan media sosial dalam melakukan strategi employer branding sesuai dengan karakteristik target calon pekerja supaya dapat meningkatkan reputasi positif dan mendorong minat melamar kerja ke perusahaan untuk memperoleh tenaga kerja berkualitas sesuai kebutuhan.

\section{DAFTAR PUSTAKA}

Aslam, S. (2015). Employer branding and intention to apply by usage of social media in banking sector, Pakistan. International Journal of Scientific \& Engineering Research, $6(5)$.

Babikova, K., \& Bucek, J. (2019). A model replication with an extension of students' perceptipn of prospective employer attractiveness. Journal of Competitiveness, 5-21.

Backhaus, K. (2016). Employer branding revisited. Organization Management Journal, 13, 193-201.

Berthon, P., Ewing, M., \& Hah, L. L. (2005). Captivating company: Dimensions of attractiveness in employer branding. International Journal of Advertising, 151-172.

Carrol, E. C. (2016). The Sage Encyclopedia of Corporate Reputation. New York: Sage Publications.

Collins, C. J., \& Stevens, C. K. (2002). The relationship between eraly recruitment-related activities and the application decisions of new labour-market entrants: A brand equity approach to recruitment. Journal of Applied Pyschology, 87, 1121-1133.

David, F. R., \& David, F. R. (2017). Strategic Management: A Competitive Advantage Apporach, Concepts and Cases. London: Pearson Education.

Deloitte. (2019, May 21). Deloitte Research Reveals a :Generation Disrupted:" Growing Up in a World of Accelerated Transformation Leaves Millenials and Gen Zs Feeling Unsettled About The Future. Retrieved November 24, 2019, from Deloitte: https://www2.deloitte.com/la/en/pages/about-deloitte/articles/deloitte-millennialsurvey-research-reveals-gen-z-unsettled-pr.html\# 
Eger, L., Micik, M., Gangur, M., \& Rehor, P. (2018). Employer branding: Exploring attractiveness dimensions in a multicultural context. Technological and Economic Development of Economy, 25, 519-541.

Fornell, C., \& Larcker, D. (1981). Evaluating structural equation models with unobservable variables and measurement error. Journal of Marketing Research, 39-50.

Gehrels, S. (2019). Employer Branding for the Hospitality and Tourism Industry: Finding and Keeping Talent. Bingley: Emerald Group Publishing.

Hair, J. F., Black, W., Babin, B., \& Anderson, R. (2014). Multivariate Data Analysis (7 ${ }^{\text {th }}$ ed.). London: Pearson Education Limited.

Highhouse, S., Lievens, F., \& Sinar, E. F. (2003). Measuring attraction to organizations. Educational and Psychological Measurement, 63, 986-1001.

Katiyar, V., \& Saini, G. K. (2016). Impact of social media activity in employer brand equity and intention to apply. NMIMS Management Review, 11-31.

Khalid, S., \& Tariq, S. (2015). Impact of employer brand on selection and recruitment process. Pakistan Economic and Social Review, 53, 351-372.

Keller, S., \& Meaney, M. (2017, November). Attracting and Retaining the Right Talent. Retrieved 12 1, 2019, from McKinsey \& Company Ogranization: https://www.mckinsey.com/business-functions/organization/our-insights/attracting-andretaining-the-right-talent\#

Kissel, P., \& Buttgen, M. (2015). Using social media to communicate employer brand identity: The impact on corporate image and employer attractiveness. Journal of Brand Management, 755-777.

Moroko, L., \& Uncles, M. D. (2008). Characteristics of successful employer brands. Brand Management, 16, 160-175.

Priyadarshini, C., Kumar, Y., \& Jha, R. R. (2017). Employer attractiveness through social media: a phenomenological study. The Qualitative Report, 22, 969-983.

Singh, A., \& Dangmei, J. (2016). Understanding the generation Z : The future workforce. South-Asian Journal of Multidisciplinary Studies.

Sivertzen, A. M., Nilsen, E. R., \& Olafsen, A. H. (2013). Employer branding: Employer attractiveness and the use of social media. Journal of Product and Brand Management, 473-383.

Streukens, S., \& Leroi-Werelds, S. (2015). Bootstrapping and PLS-SEM: A step-by-step guide to get more out of your bootstrap results. European Management Journal.

Turban, D. B., Forret, M. L., \& Hendrickson, C. L. (1998). Applicant attraction to firms: Influences of organization reputation, job and organizational attributes, and recruiter behaviors. Journal of Vocational Behavior, 52, 24-44.

Tuten, T. L., \& Solomon, M. R. (2014). Social Media Marketing. California: Sage.

Wei, Y. C., Chang, C. C., Lin, L. Y., \& Liang, S.-C. (2015). A fit persepective approach in linking corporate image and intention to apply. Journal of Business Research. 